УДК 78.03

\title{
Ню Нин \\ ПРИНЦИПЫ ФОРМООБРАЗОВАНИЯ ОДНОЧАСТНОЙ МУЗЫКАЛЬНОЙ КОМПОЗИЦИИ (НА ПРИМЕРЕ ПЬЕСЫ Ф. ШУМАНА «ПОРЫВ»)
}

В статье введено понятие «рондо-сонатная одночастность», рассматриваются свойства формы рондо-сонатной одночастности и анализируются ее особенности на примере фортепианной пьесы Р. Шумана из «Фантастических пьес» ор. 12 - «Порыв». Подводятся итоги целостного анализа пьесы с точки зрения рондо-сонатной одночастности: многотемность, стремление к замкнутости разделов и также к сквозному развитию, с двойственной трактовкой основной тональности; также с нарушенной масштабной соотносительностью рефренов и эпизодов, разделов формы.

Ключевые слова: одночастность, рондо-соната, многотемность, целостный анализ, замкнутость и разомкнутость, тональная двойственность, внутреннее развитие, Шуман, «Порыв».

Одночастное произведение может заключать в себе как композиционные признаки формы сонаты, так и формы рондо-сонаты. Как известно, основные черты рондо-сонатной формы - повторение темы главной партии в главной тональности в конце экспозиции (т. е. после традиционной экспозиции). В эпоху романтизма, и без этого условия сближение сонаты и рондо оказалось возможным на почве повторения главной темы - рефрена (темы главной партии), проходящего не только в основной, но и в подчиненной тональности; причем это может происходить в начале или внутри разработки, или вместо нее; полностью или частично; точно или вариантно.

К такому виду рондо-сонатной одночастности относится «Порыв» Роберта Шумана - фортепианная пьеса из сборника «Фантастические пьесы», ор. 12 - известнейшая и впечатляющая. Это образец рондо-сонатной одночастности, весьма своеобразно трактованной: с тенденцией к многотемности и определенной самостоятельности разделов (тема рефрена, т. е. главная партия), но и с тенденцией к сквозному развитию (темы побочной партии, эпизода), а также с нарушенной масштабной соотносительностью рефренов и эпизодов.

Отметим сразу образную самостоятельность, особенности внутреннего строения и замкнутость рефрена, созданного в форме вариантно

(C) Ню Нин, 2015 
повторенного периода (А-А1 $=8+8$ тактов). Все это делает главную партию рондо-сонатной формы образно независимой в драматургии пьесы. Рефрен сложный технически и требует «больших рук» пианиста, т. к. невозможно иначе охватить диапазон мелодической линии и сопровождающего ее аккордового остинато, причем постепенно заполняющегося дополнительными звуками (см. рефрен в начале репризы рондо-сонатной формы).

Первая фраза темы первоначально излагается в нижнем голосе аккордов правой руки, начинаясь со слабой доли такта (с пятой доли), со стремительным восходящим диатоническим ходом, с остинатной ритмической дублировкой терций верхнего голоса. Резкая активность данной фразы подчеркивается не только ритмически, но и повторами аккордов без их задержаний на сильной и относительно сильной доли такта. Обратим внимание, что в начальной фразе темы отсутствует тональная опора, т. е. тоника, т. к. господствует субдоминантовая гармония при размере $6 / 8$ в тональности f-moll: s-| s6-s-s-II-II2-| II2-D6/5 (2 такта). Затем следует точный повтор фразы, эти фразы и составляют первое предложение.

На гране завершения первой фразы в басу звучит реплика скачков из трех доминантовых октав crescendo C-c-c1. Затем начало второй фразы усилено sF октавы до большой и контроктавы. Яркость фразы также поддерживается разрывом диапазона мелодической линии, в которой господствует субдоминанта и доминантовое сопровождение в басу.

Вторая фраза контрастна первой. Она цельная, наполнена сложнейшей полиритмией, с нисходящей мелодической направленностью. Наконец-то появляется тоника, а затем субдоминанта f-moll приравнивается ко второй ступени параллельной тональности As-dur, которая активно закрепляется четким кадансом (t6s=II-II6-| K6/4-D7-| T). Тема здесь сопровождается гармонической фигурацией с опорой на сильную и относительно сильную доли такта.

Второй повторенный период усилен поддержкой в начале первой фразы, как и в начале второй, sF октавы ноты «до» большой и контроктавы.

Образуется вариантно повторенный модулирующий период, в форме которого создан рефрен рондо-сонаты, т. е. ее главная партия.

Схема строения ГП-рефрена: 


\begin{tabular}{|c|c|}
\hline A & $\mathrm{A} 1$ \\
\hline $\mathrm{a}++_{\mathrm{B}}$ & $\begin{array}{ll}\text { a } 1 & + \text { в } 1\end{array}$ \\
\hline $4(2+2)+4$ & $4(2+2)+4$ \\
\hline 8 & 8 \\
\hline f $\quad-$ As & f $\quad-$ As \\
\hline
\end{tabular}

Рефрен звучит в пьесе еще три раза. Вторично - после экспозиции. В нем наблюдаются черты вариантности (басовая октава перемешается до начала мелодической фразы), развития и нарушения формы строения: добавлено еще одно развивающее предложение a2+ a3/p (p - разработочность) + в2. Во «вставном» предложении композитор вводит имитацию первого тематического мотива, удвоенного остинато звука «с». Вместе с удвоением основной фразы терцией «es-ges» образуется уменьшенное трезвучие («c-es-ges»). Также этот рефрен не модулирует, утверждая основную тональность f-moll.

Схема строения второго проведения ГП-рефрена:

\begin{tabular}{|c|}
\hline A2 \\
\hline a $2 \quad+\mathrm{a} 3 / \mathrm{p} \quad+$ B \\
\hline $4(2+2)+4(2+2)+4$ \\
\hline 12 \\
\hline f $-\quad$ b-moll f-moll \\
\hline
\end{tabular}

Третье появление рефрена (после предъикта), предваряемое нисходящим гаммообразным движением баса, начинает репризу. Интересно использован имитационно-дублирующий голос: октавно имитируется лишь начальная трехзвучная интонация, а затем также октавно удваивается мелодический голос. Здесь звучит вариант лишь одного периода (модулирующего), без повтора.

Последний рефрен звучит в конце произведения. Он вновь не модулируюший, сокращенный до одного периода и завершающийся полноценными аккордами: Д4/3 - t.

Рассмотрим эпизоды. Первый и третий эпизоды - выполняют функцию побочной партии в рондо-сонатной форме. Побочная партия также самостоятельная, но очень развитая, большая, с нарушенной масштабностью (по сравнению с главной партией): ГП - 16 тактов (дважды повторенный период, т. е. композитору пришлось дважды повторить период, чтобы хотя бы как-то уравнять масштабно с остальными разделами - эпизодами); ПП - 24 такта (простая трехчастная форма). 
Созданная Шуманом побочная партия (первый эпизод рондо-сонаты) написана в простой трехчастной форме, она наполнена чертами вариантности, фактурного развития.

Если главная партия здесь активная, напористая, порывистая, что полностью соответствует названию пьесы - «Порыв», то побочная партия - стремительная, но наполненная глубоко спрятанной внутренней жалобой: начиная со слабой доли (с четвертой), восходящий стремительный хроматический ход (f-ges-g), доходящий до ламентовской секундовой интонации на вершине (b-a) - сильной доли в конце фразы (два такта). В верхнем голосе выходит на поверхность мелодия, сопровождающаяся гармоническими фигурациями и аккордами в нижних голосах: as-a-b-as (оркестровая фактура).

Четырехлинеарная фактура побочной партии содержит две мелодические линии: сопрановая - основная. Каждый звук мелодии дважды повторен - как бы основной и его эхо. Мелодия частично поддержана в теноре (дуэтное движение сопрано и альта). У альта гармонические фигурации, причем отметим ритмическое дробление в размере 6/8 на постоянном движении шестнадцатых. У баса - гармоническая поддержка: выдержанная тоника и вводный тон в Des-dur (для основной тональности f-moll это VI ступень; для тональности, в которую модулирует главная партия - As-dur, - это тональность субдоминанты).

Построение темы аналогично главной партии: двухтактная фраза -2 такта, затем ее повтор -2 такта и потом обобщенная фраза 4 такта. Но драматургия темы иная: две волны $(2+2$ такта), затем столь же постепенный спад.

Первый период побочной партии и главной партии - единый, однотональный, нормативный, состоящий из двух контрастных предложений $(4+4)$, As-dur.

Средняя часть побочной партии - первого эпизода рондо-сонаты пьесы - объединена с первой частью единым фактурным и ритмическим содержанием сопровождающей линии, из которой периодически (на второй и четвертой доле) возникает мелодия. Но меняются агогические особенности линии: стаккато на слабых долях (вторая и шестая, восьмая и двенадцатая доли групп равномерных шестнадцатых).

Здесь нарушается принцип внутреннего строения периода: нет внутренних повторов, предложения восходящие текут секвентно. Фразы по-прежнему контрастны: вверх идущая линия нижнего го- 
лоса - гамма Des-dur c VI натуральной и VI\# ступенями, как бы продолжающая линию первого периода побочной партии, а затем возвращающаяся к его первому предложению.

Секвентное второе предложение середины побочной партии гамма es-moll'ная (5-6 такты темы) и возвращение-модуляция в Desdur (7-8 такты).

Реприза простой трехчастной формы побочной партии - динамическая. В первом ее предложении полностью сохраняется мелодическая и фактурная линия правой руки. Сохраняется также линия «тенора», перенесенная на вторую и пятую доли, создавая синкопированность к мелодии, усиливая ее значимость и дополняя тематический план. Фактура сопровождения производна от второго предложения главной партии.

Функции фактуры как бы меняются местами. Второе предложение репризы побочной партии возвращает гармонию экспозиции, но перенесенное на октаву ниже расширяет разрыв диапазона двух ведущих планов правой и левой рук.

Схема строения первого эпизода - побочной партии - в экспозиции (простая трехчастная форма):

\begin{tabular}{|c|c|c|}
\hline Экспозиция & Эпизод & Реприза \\
\hline $\mathrm{B}$ & $\mathrm{C}$ & $\mathrm{B} 1$ \\
\hline $\mathrm{c}+\mathrm{d}$ & $\mathrm{e}+\mathrm{e} 1$ & $\mathrm{c} 1+\mathrm{d} 1$ \\
\hline 8 & 8 & 8 \\
\hline $4+4$ & $4+4$ & $4+4$ \\
\hline (фразы: $2+2+4)$ & & (фразы: $2=2+4)$ \\
\hline Des-dur & Des-es-Des & Des \\
\hline VI & VI & VI \\
\hline
\end{tabular}

Итак, побочная партия в рондо-сонатной форме представлена в тональности VI ступени к основной f-moll; и субдоминанты относительно тональности, в которую модулирует главная партия - As-dur.

Второе проведение побочной партии (первого эпизода в рондосонатной форме «Порыва») встречаем в репризе. Она идентична экспозиционной масштабно, фактурно. Меняется лишь тональное содержание темы на As-dur, т. е. на тональность третей ступени относительно основной f-moll и в тональности, в которую приводит развитие главной партии (f-moll - As-dur).

Таким образом, можно сделать вывод, что в пьесе «Порыв» в наличии две основные тональности: f-moll и As-dur. Аналогичная двуто- 
нальность наблюдалась и в «Фантазии» Ф. Шопена, причем там даже оказались те же тональные основы: f-moll и As-dur.

В тональном плане классическая сонатная форма, как известно, стабильна: побочная партия экспозиции оказывается в тональности доминанты относительно основной или в параллельной к минору, т. е. происходит сопоставление достаточно ярких тональностей; в репризе происходит сближение тональностей главной и побочной партии, т. е. обычно они аналогичны.

Но в романтической сонате наблюдается иное взаимодействие тональностей: в экспозиции происходит сопоставление достаточно далеких тональностей, в репризе - тональности сближаются.

Здесь же, в пьесе «Порыв», главная партия модулирующая, из минора в параллельный мажор: f-moll - As-dur (характерный тональный план для произведений И. С. Баха, например, в Инвенциях), поэтому параллельная тональность трактуется как близкая основной. Вот в ней (As-dur) и создается побочная партия репризы рондо-сонатной формы. Таким образом, тональный план «Порыва» не стандартный.

Также не стандартно и масштабное соотношение главной и побочной партий: 16 тактов, т. е. дважды повторенный вариантный период в ГП; и 24 такта, простая трехчастная форма в ПП.

Особое внимание следует обратить на срединный эпизод (второй в рондо-сонате), который появляется вместо разработки. Эпизод значительно расширяет значимость многотемности в произведении, дает возможность предположить, что рондо-сонатная одночастность пьесы «Порыв» ведет к циклической одночастности.

Итак, в срединном эпизоде проявляется тенденция к многотемности, тематической контрастности, с тенденцией к сквозному развитию (периоды D-E-F), хотя и наблюдается репризность (D......D1). Эпизод создан в трехчастной форме с составной серединой.

Основная тональность срединного эпизода B-dur, т. е. далекая тональность к основной f-moll (мажорная субдоминанта) и относительно второй основной тональности As-dur - т. е. вторая мажорная. Таким образом, срединный эпизод совершенно самостоятельный, обособленный от экспозиции и репризы.

Основная тема эпизода наполнена взволнованной лиричностью (B-dur). Сопровождение фактурно вновь аналогично главной партии, но с опорой на сильную и относительно сильную доли такта. Опорные басы создают дуэтную полифонию к тематической линии, изложенной октавами либо аккордами. Во втором предложении ме- 
лодизированные аккорды вместе с сопровождающими линиями все ниже опускаются (басовый ключ).

Период (D) нормативный, состоит из двух предложений относительно контрастных друг другу (во всяком случае, направленностью и содержанием мелодической линии, но не фактурой).

Если в основе мелодической линии экспозиции эпизода (D) находится секвенция нисходящих кварт с терцовым шагом, то в первом периоде середины (Е) - секвенция восходящих терций с секундовым. Происходит фактурное насыщение, но и упрощение - удвоение восходящего движения, начиная от низкого регистра у альта и баса в дециму. Мелодия отдается верхнему голосу, тенор лишь условно гармонически его поддерживает.

Здесь (Е) вновь форма периода, состоящего из двух контрастных предложений (4+4 такта) и дополнения, состоящего из вычленения и точного повтора двух последних тактов второго предложения (2 такта). Во втором предложении содержится ряд отклонений и модуляции: B-c-g-c-Es (так что обновляется форма периода в пьесе - ненормативный).

После замедления в конце первого периода срединного эпизода (D), во втором (E) вновь восстанавливается первоначальный темп и впервые в произведении появляется обозначение-ремарка scherzando.

Теперь, в процессе сквозного развития, следует новый период срединного характера $(\mathrm{F})$, состоящего из трех предложений секвентного соотношения $(1+11+12)$, гармонически неустойчивых и разомкнутых. Ремарка scherzando полностью соответствует содержанию периода: начинаются $\mathrm{sF}$ и октавное стаккато во вторых тактах предложений. Это добавляет в пьесу ошущение игривости, танцевальности. скерцозности.

После связки, содержащей нисходящую гамму B-dur при замедлении темпа (ritardando), возвращается точная реприза, создавая репризность в трехчастности срединного эпизода с составной серединой.

Схема строения срединного эпизода формы рондо-сонаты:

\begin{tabular}{|c|c|c|c|c|}
\hline $\mathrm{D}$ & $\mathrm{E}$ & $\mathrm{F}$ & связка & $\mathrm{D} 1$ \\
\hline $\mathrm{f}+\mathrm{g}$ & $\mathrm{H}+\mathrm{k}$ & $1+11+12$ & & $\mathrm{f}+\mathrm{g}$ \\
\hline 8 & 10 & 12 & 2 & 8 \\
\hline $4+4$ & $4+4+2$ & $4+4+4$ & & $4+4$ \\
\hline В-dur & B c-g-c-Es & c c- Des - As-d & В & B-dur \\
\hline Экспозиция & \multicolumn{5}{|c|}{ Средняя часть связка } & Реприза точная \\
\hline
\end{tabular}


Из завершения эпизода естественно вытекает предъикт к репризе рондо-сонатной формы. Это типичный предъикт, достаточно расширенный (22 такта). Постоянное нисходящее гаммообразное движение низких басов и восходящее выдержанное (половинные с точкой) хроматическое аккордовое движение, охватывающее малую и первую октавы (S-DD\#1-T в B-dur). Обычен для предъикта четырехтактовый повтор (4 + 4 такта); следующие 4 такта - гармоническая трансформация при такой же фактуре.

На фоне такого же гаммообразного движения появляются отрезки лейттемы (начальная фраза рефрена): сперва трехзвучные, затем пятизвучные, как бы развивающие фразы (мелодия 3-аккордовая, 5-аккордовая в басовом ключе; 3-аккордовая, 5-аккордовая; и вновь 5-аккордовая - уже в скрипичном). И теперь наступает реприза рондо-сонатной формы.

O рефренах - главной партии и в первом (а также третьем) эпизоде - побочной партии - уже шла речь. Поэтому можно подвести итоги.

В результате проделанного анализа мы пришли к следующим выводам. Форма рондо-сонаты в пьесе Шумана «Прорыв» трактована весьма своеобразно:

- с тенденцией к многотемности (в произведении 6 различных тем);

- со стремлением к определенной самостоятельности, замкнутости разделов (тема рефрена, т. е. период главной партии; простая трехчастная побочная партия; срединный эпизод - трехчастная репризная форма с составной серединой);

- но и с тенденцией к сквозному развитию (темы побочной партии, три темы срединного эпизода);

- с определенной фактурной общностью эпизодов: в побочной партии это движение шестнадцатых с различными временными опорами; в срединном эпизоде - постоянный фон восьмых (при том же размере 6/8), опять-таки с вариантностью временных опор;

- главная партия модулирующая - из минора в тональность III ступени; в экспозиции побочная создана в тональности VI ступени, а в репризе - в тональности III ступени, т. е. параллельной;

- а также с нарушенной масштабной соотносительностью рефренов и эпизодов, разделов формы: $16(8+8)+24+24+62(40+22)+8+24+8$.

Таким образом, Пьеса «Порыв» из сборника «Фантастические пьесы», ор. 12 Роберта Шумана - образец рондо-сонатной одночастности. 
Ню Нін. Принципи формоутворення одночастинної музичної композицї̈ (на прикладі п'єси Ф. Шумана «Порив»). В статті введено поняття «рондо-сонатна одночастинність», розглядаються особливості форми рондо-сонатної одночастинності й аналізуються іiі особливості на прикладі фортепіанної п'єси Ф. Шумана 3 «Фантастичних п’єс» ор. $12-$ «Порив». Подводяться підсумки цілісного анализу п'єси з точки зору рондо-сонатної одночастинності: багатотемність, потяг до замкнутості розділов і також до наскрізного розвитку, 3 подвійною трактовкою основної тональності; з порушеною масштабністю співвідношення рефренів та епізодів, розділів форми.

Ключові слова: одночастинність, рондо-соната, багатотемність, цілісний аналіз, замкнутість та разімкнутість, тональна подвійність, внутрішнній розвиток, Шуман, «Порив».

$\mathrm{Nu}$ Nin. Principles of forming one-part musical composition (for the example plays F. Schumann "Rush"). The article introduces a concept «one-part rondo-sonata», considers features of one-part rondo-sonata form and analyzes its peculiarities in terms of a piano play by R. Schumann «Fantastic pieces», op. 12 - «Rush». There are results of the comprehensive analysis of the play from the point of view of onepart rondo-sonata: polytheme, tendency for completeness of the parts and for a through development, with double interpretation of the main tonality; aw well as with the broken scale correlativeness of refrains and episodes, parts of the form.

Keywords: one-part form, rondo-sonata, polytheme, comprehensive analysis, completeness and incompleteness, tonal duality, internal development, Schumann: «Rush». 